\title{
Studying the coating of Alumina and Hydroxy Apatite on Tapered Dental Implant (In Vivo and In Vitro Study) \\ Raghdaa K Jassim
}

B D S, MSc, PhD, Ass.Prof University of Baghdad, College of Dentistry,Prosthodontics department.

Yaarob M Salman

B D S, MSc, PhD Ph.D student

Thair L Alzubaydi

B D S, MSc ,PhD - Senior Scientific Researcher, Ministry of Science andTechnology,Baghdad,Iraq

\begin{abstract}
\end{abstract}
Background: In clinical trial studies, the success of dental implant depends on excellent biocompatibility, mechanical strength and characteristic of material such as surface properties of material.

The Objective of this study was to evaluate the effects of coating implants with two materials (Al2O3 \&HA).And this was in mixture form or in two layers form. Then their effect on the bond strength at the bone/implant interface with cell compatibility was evaluated.

Materials and methods: Electrophoretic deposition technique (EPD) was used to obtain a uniform coating for each one of two types of coated layers on the screws (mixture of 50\% HA and 50\% Alumina and two layers). For examination of the changes occurred on the surface, structural, elemental analysis and morphological investigations were carried out on the modified surfaces of the Ti-6Al-7Nb alloy using different techniques, namely X-ray diffraction (XRD), and Energy Dispersive X-ray Fluorescence (EDXRF). The in vivo study was done by the implantation of tapered screw-shaped uncoated and coated implants of $3 \mathrm{~mm}$ diameter, $8 \mathrm{~mm}$ length (the threaded part is $5 \mathrm{~mm}$ and the smooth part is $3 \mathrm{~mm}$ ) and $0.5 \mathrm{~mm}$ pitch height.The tibia of white New Zealand rabbits were chosen as implantation sites. The right tibia of rabbit received two screws, (one uncoated and coated) while the left tibia of a rabbit received coated screws of two layers. To understand the bone-implant interface, biomechanical test was performed after 2, 6 and 18 weeks healing periods. 15 rabbits were sacrificed for each period. A removal torque was done for ten animals in each group, whereas the other five ones were used for histological testing with optical microscope.

Results: The results indicates that there was a rapid reaction of bone towards coated Ti-6Al-7Nb alloy implants as compared with the uncoated one and more mature bone was observed after 6 weeks of implantation in screws coated with a mixture of Alumina and HA. The biomechanical test revealed that there was an increase in the torque mean value at bone-implant interface with time, with the highest mean values of bond strength in implants coated with a mixture of $50 \% \mathrm{HA}$ and $50 \%$ Alumina. Also the bond strength of two layers coating was more than that of uncoated.

The results of histological examination revealed a well tissue response with the formation of a lamellate and haversian type of osteon tissue after 18 weeks.

Conclusion: this study concludes that coating by electrophoresis proved to be a valuable process to coat metallic implants with an osteoconductive material, and to form a uniform biocomposite and multiple layer coating. The biomechanical and biological properties of the bone-implant interface associated with the coated implants were improved comparing to the uncoated ones they have better mechanical properties and excellent biocompatibility through the improved performance of bone at the site of a bone implant contact area than the uncoated implants.

KEY WORDS : EPD, Alumina, Hydroxyapatite, implant

CITE THIS ARTCLE:

Jassim R,Salman Y, Alzubaydi T.Studying the coating of Alumina and Hydroxy Apatite on Tapered Dental Implant (In Vivo and In Vitro Study). Iraqi Dent. J. 2016; 38(1):12-20. http://www.iraqidentaljournal.com

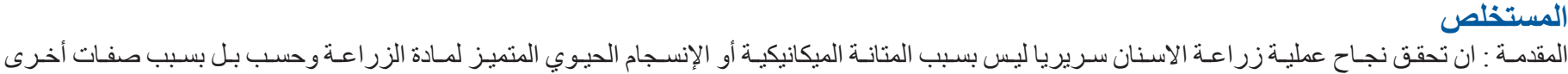

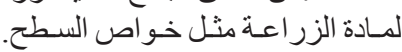

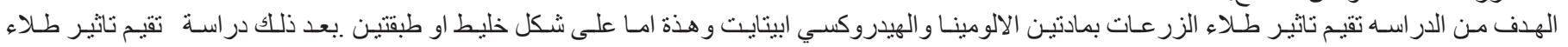

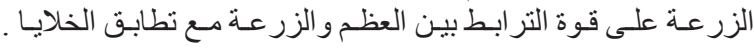

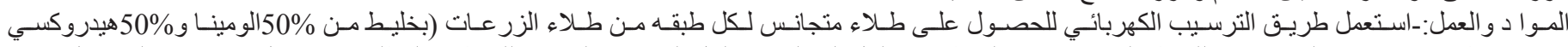

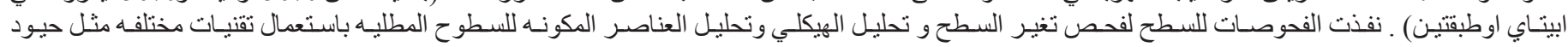

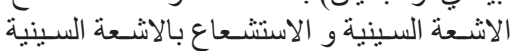

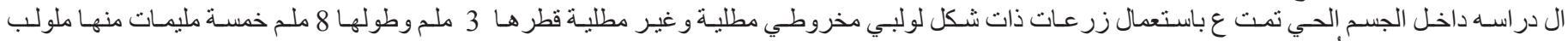

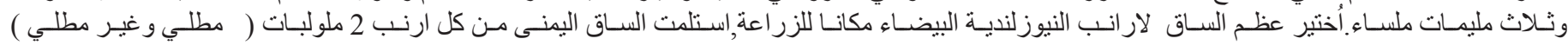

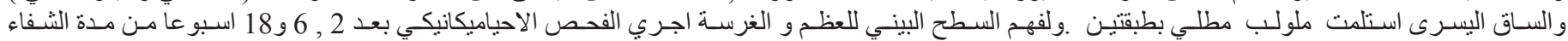

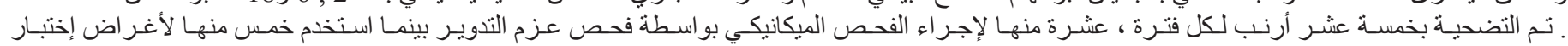

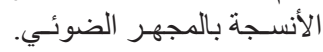

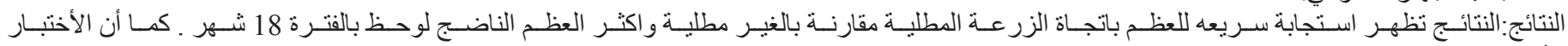

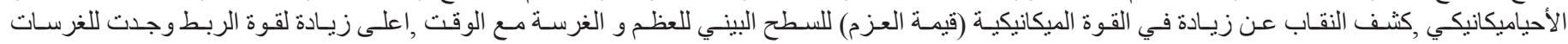

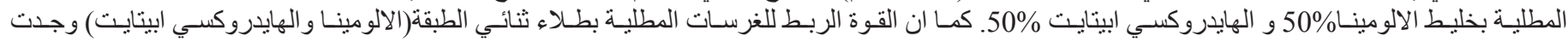

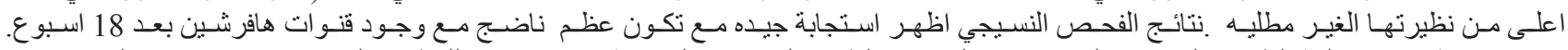

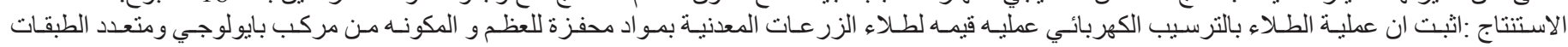

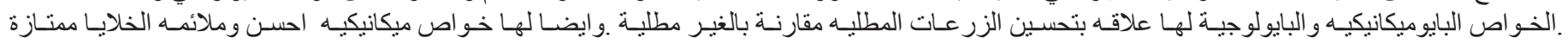

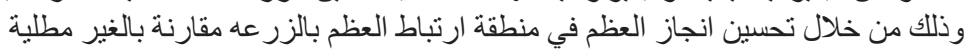




\section{INTRODUCTION}

The ultimate goal of using implants is the prosthetic rehabilitation of patients with lost dentition, for both the functional and esthetic levels ${ }^{(1)}$.Surface modification of dental implant is still a very active area of research. And a definite interest exists in surface treatment that can induce normal healing phenomena and restoring implants sooner than that was previously believed possible ${ }^{(2,3)}$.One reason is the fact that the physical or chemical and biochemical properties of the implant surface control the performance of relevant processes such as protein adsorption and cell surface interaction at the interface between the biomaterial and the body ${ }^{(4)}$.The development of coating system was driven by combining the mechanical properties of metallic implant material with the bioactivity of ceramics material ${ }^{(5)}$. Ceramic materials used in surgery can either be bioinert or bioactive .Alumina is an excellent biomaterial with good biocompatibility, high wear resistance, high strength and high corrosion resistance.it was used in hip prostheses and dental implant. If the bioactivity to alumina is imparted, the range of its application as biomaterial will be largely extended (6).

Hydroxyapatite, (HA), $\mathrm{Ca}_{10}(\mathrm{PO} 4)_{6}(\mathrm{OH})_{2}$ is a natural mineral found in human enamel and bone ${ }^{(7)}$. Bioactive HA is deposited onto implants surfaces to promote bone formation and enhance bone - implant adhesion. While bone compatibility is provided by the HA the underlying metal possesses good strength and ductility. HA coatings has been achieved by a number of methods, including ion implantation, plasma spraying, , sputtering, sol-gel coating, bioimmic methods, and electrophoretic deposition meth od $\mathrm{s}^{(8)}$

Electrophoretic deposition (EPD) is considered as a colloidal forming technique. In this technique, and in a stable suspension, the charged colloidal particles ar e deposited on a positively charged substrate after the application of an electric field. EPD technique gained a great attention in processing of ceramic materials and coatings. This is because of its cost-effectiven ess and requires simple apparatus, alsoits can be deposited on complex geometry ${ }^{(9)}$.

The development of coating system by forming a two layers co ating (bioinert ceramic inner layer and bioactive outer shell) and by mixing of bioactive with bioinert ceramic materials so as to improve its biocompatibility and mechanical properties, beside the induction of osseointegration should be evaluated.

In this study, in vivo investigation of ceramics films using catho dic electrophoretic deposition on
Ti-6Al-7Nb was performed to evaluate the behavior of this modified alloy by this technique histologically and mechanically

\section{MATERIALS AND METHODS}

\section{Electrophoretic deposition process includes:-}

A-Suspension preparation:

$1^{\text {st }}$ Suspension $\mathrm{p}$ r eparation used for coating a mixture of hy $\mathrm{d} r$ oxyapatite HA (Particles size $3.8 \mu \mathrm{m}$, Merck, D a r mstadt, Germany).and $\mathrm{Al}_{2} \mathrm{O}_{3}$ (Particles size $(8.7 \mu \mathrm{m})$, Riedel-de Haën $\mathrm{AG}$ in Seelze Hannover, Germany) was prepare as follow:Adding $50 \% \mathrm{HA}+50 \% \mathrm{Al}_{2} \mathrm{O}_{3}$ powders to the solvent (ethanol) (100g/1 liter) in a container over a stirrer for 10 minutes. After that phosphate ester $(3.5 \mathrm{~g} / 1$ liter $)$ as dispersant agent was added. After stirring for 10 minutes. Polyvinylbutyral was added as a binder (3g/1 liter). The stirring was continued until a colloidal suspension was obtained. $2^{\text {nd }}$ suspension was used for Alumina coating. The suspension was prepared by adding alumina powder to solvent (ethanol) $(100 \mathrm{~g} / 1$ liter) in a container over a stirrer for $10 \mathrm{~min}$. dispersant agent was added, this was the phosphate ester $(3.5 \mathrm{~g} / 1$ liter). After stirring the polyvinylbutyral was added as a binder ( $3 \mathrm{~g} / 1$ liter).The stirring continued until a colloidal suspension was obtained ${ }^{(10)}$.

B- Coating process: The Ti-6Al-7Nb specimen was placed on the cathode and anode electrode. The distance between two electrodes was $10 \mathrm{~mm}$. Then both electrodes were connected to the power supply and a meter. In order to understand the effects of time on the coating thickness, the power supply was used with $(60 \mathrm{~V})$ for coating the $\mathrm{Al}_{2} \mathrm{O}_{3}$ and a mixture of $\mathrm{HA}$ and $\mathrm{Al}_{2} \mathrm{O}_{3}$, the coating procedure was repeated for a periods of time 2, 3, 4, 5,6 and 7 min. while $(10 \mathrm{~V})$ was used for coating the $\mathrm{HA}$ in the same procedure which was repeated for periods of time 5, 10,15,20,25\&30 min. ${ }^{(10)}$

Another pilot study has been done to understand the effect of applied voltage on the coating thickness, the power supply was used with different applied voltage $(10,20,30,40,50 \& 60 \mathrm{~V})$ for $5 \mathrm{~min}$ for coating the alumina and a mixture of hydroxyapatite and alumina. Also the same procedure was repeated with different applied voltage $(5,10,15,20,25 \&$ $30 \mathrm{~V}$ ) for $5 \mathrm{~min}$ for coating the hydroxyapatite. After evaluation of the results of the coating of $\mathrm{Al}_{2} \mathrm{O}_{3}$ and HA with different applied voltage and time periods, the specimens were coated with $\mathrm{Al}_{2} \mathrm{O}_{3}(5 \mathrm{~min}, 60 \mathrm{~V})$ as first inner layer and then coated with HA (5 min, $10 \mathrm{~V}$ ) as second outer shell layer.

After complete coating, Sintering was carried out using Tubed furnace (Carbolite Type MTF 12/38A. 
BAMFORD England). The treatment temperature is $850{ }^{\circ} \mathrm{C}$ for specimens coated with a mixture of HA and alumina powder, whereas $800^{\circ} \mathrm{C}$ for two hours is given to those coated with two layers ${ }^{(11,8)}$

After complete sintering of specimens, examination of coated layer is performed using the following:-

\section{A Thickness measurement:}

For all samples, measurements of coating layer thickness was performed using microprocess coating thickness gauge (ERICHSEN MINI test 3000).

\section{B. Microscopical examination:}

Examination of the coated layer was performed using optical microscope (Nikon Type 120, Japan) provided with a digital camera type DXM $1200 \mathrm{~F}$. The micrographs were analyzed through Nikon ACT- version 2.62, 2000 software. This procedure is applied for coated sample at different times and different applied voltage.

\section{X-Ray phase analysis XRD}

Phase analysis is employed on Ti-6Al$7 \mathrm{Nb}$ alloy specimen before and after coating. Phase analysis was studied using 3121 powders X-ray Diffractometer using $\mathrm{Cu}$ Ka radiation. The 2Oangles were swept from $20-60^{\circ}$ in step of one degree. The peak indexing was carried out based on the JCPDS (joint committee on powder diffraction standards).

\section{D.X-Ray Fluorescence (XRF)}

it is an elemental analysis technique. And it is used in determinations of the major elements Also it can make a broad elemental survey of the sample composition without standards. Energy dispersive XRF (EDXRF) was performed to determine the composition of the coated layer as well as the matrix elements.

\section{E. Microhardness measurement:}

Vickers Micro Hardness Tester (Micro met ADOLPH 1. BUEHLER INC.Optical and metallogrical instrument $2120 \mathrm{Gr} / \mathrm{USA}$ ). Measurement of the microhardness was performed for samples coated with a mixture of 50\% Hydroxyapatite and $50 \%$ Alumina, b. two coating layers (Alumina layer and HA layer) c. Uncoated samples.

\section{Implant preparation:}

Ti-6Al-7Nb alloy rod machined into tapered screw-shaped implants using a Lathe machine. The rod was $6 \mathrm{~mm}$ in diameter (ASTM F1295, Straumann Company, Switzerland). The diameter of each screw $3.0 \mathrm{~mm}$ and the length about $8 \mathrm{~mm} \quad(5 \mathrm{~mm}$ is the threaded part and $3 \mathrm{~mm}$ is the smooth part) with pitch height was $0.5 \mathrm{~mm}$. Tapering angle is $6^{\circ}$. The head of the implant had a slit to fit the torque meter during insertion and mechanical testing. After that all implants cleaned with ethanol for 15 minutes in an ultrasonic cleaning device. Then specimens were dried at $100^{\circ} \mathrm{C}$. The screws were divided into three groups each group consist of forty five screws.

The $1^{\text {st }}$ group was coated with a mixture of HA and alumina for $5 \mathrm{~min}$ with $60 \mathrm{~V}$ following the same procedure of EPD that was performed on the Ti6 A 17Nb alloy specimens. $2^{\text {nd }}$ group was coated with two layers (inner layer alumina for $5 \mathrm{~min}$ with 60 $\mathrm{V}$ \& outer layer HA for $5 \mathrm{~min}$ with $5 \mathrm{~V}$ ). The last $3 \mathrm{rd}$ group uncoated screws were passivated in $28 \%$ nitric acid for one hour and then rinsed with an ultrasonic cleaning device for 5 minutes.

\section{Sterilization of implants}

"The screws were sterilized according to the usual irradiation dose recommended for sterilization of s urgical instrument and materials." (12)

\section{Sample grouping}

Implants were categorized according to the type of test into:

\section{Mechanical test (torque measurements)}

a.Control group (30 uncoated implants): This group includes 10 implants for each healing interval $(2,6$ and 18 weeks).

b.Experimental group :-( 60coated implants): in which the screws were divided according to the type of material that was used in the coating process into:

i. Coated with a mixture of HA\& alumina powder: 10 screws for each healing interval.

ii. Coated with two layers (inner layer alumina \&outer layer HA): 10 screws for each healing interval.

\section{Histological test}

1. Control group (15 uncoated screws): include 5 screws for each healing interval or period $(2,6$, and 18 weeks).2.Coated with mixture of HA\& alumina powder: 5 screws for each healing period.iv - Coated with two layers (inner layer alumina \&outer layer HA): 5 screws for each healing period.

\section{Surgical Method for implantation Procedure}

Adult white male New Zealand rabbits weighing $2-3 \mathrm{~kg}$ were used. The age of the animals was from 10-12 months. Intramuscular Ivome injection was given to the animals. Also an antibiotic cover with oxytetracycline $20 \% \quad(0.7 \mathrm{ml} / \mathrm{kg}) \quad$ intramuscular injection was given.

A total of forty five animals were divided into 3 groups according to healing interval (2, 6 and 18 weeks).Each healing intervals consist of 15 animals, 5 rabbit for histological study, and 10 for mechanical test by torque removal test .Three implants (one uncoated, two coated [one coated with the mixture 
of alumina \&HA and the other one coated with two layer (inner layer alumina \&outer layer HA)] were implanted in the left tibia

"All towels and instruments were autoclaved at $121 \mathrm{C}^{\circ}$ and 15 bars for 30 minutes. The rabbit was

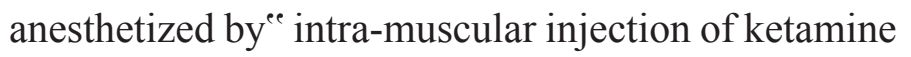
hydrochloride $50 \mathrm{mg}(1 \mathrm{ml} / \mathrm{kg}$ body weight $)$ and xylocaine $10 \%(1 \mathrm{ml} / \mathrm{kg}$ body weight). Then both tibia were shaved with a shaving spray, and the skin was cleaned with a mixture of ethanol and iodine. After that tibia was exposed. The distance between holes was $10 \mathrm{~mm}$ between them. Bone penetration was performed at a rotary speed of $1500 \mathrm{rpm}$ with irrigation "(11) .Then implant was screwed with a torque meter. Implantation of 1 screws was done in the right tibia and 2 screws in the left tibia. After suturing, local antibiotic (oxytetracycline spray) and systemic antibiotic oxytetracycline $20 \%(0.7 \mathrm{ml} / 1 \mathrm{~kg})$ was given to the rabbit. Post-operative antibiotic (local and systemic) was given for 5 days. Then the animals were followed for 2, 6 and 18 weeks

\section{Mechanical testing}

For each healing interval (2, 6 \&18 week), before mechanical test, an X-ray was taken to the implantation site. Then anesthesia given to the animals as in implantation procedure. Then surgical procedure was performed to expose the implant head. A torque meter (STURTEVANT RICHMONT TORQUE PRODUCT, MODEL F 80-1-0. USA.) used to determine the maximum torque requires to unscrew the implant from its site

\section{Histology test}

In this test, a bone- implant block was prepared by cutting of the bone around the implant $5 \mathrm{~mm}$ away from the head of the implant. Then immediately, Bone implant blocks were placed in $10 \%$ of fresh formalin for 3 days for fixation. After that, specimens were left in a solution of $10 \%$ formic acid and sodium citrate . Decalcification takes from two to three weeks. Then specimens was tested for complete decalcification by methods used by Baker et al $2009^{(13)}$

\section{Statistical methods}

The suitable statistical methods were used. These include: - a. Descriptive statistics and b. Inferential statistics a. testing equality of means value by analysis of variance (ANOVA). In all multiple comparisons significant $\mathrm{p}$-value was at $(\mathrm{p}<0.05) . b$. Least Significant Difference (LSD) after the analysis of variance.

\section{RESULTS}

a.In vivo test: Figure (1) shows series of micrographs for the microstructure of $\underline{\mathbf{a}} .^{\text {st }}$ layer of $\mathrm{Al}_{2} \mathrm{O}_{3}$ at $60 \mathrm{~V}$ for $5 \mathrm{~min} 60 \mathrm{~V}$ b. mixture of $\mathrm{Al}_{2} \mathrm{O}_{3} \& \mathrm{HA}$ for $2 \mathrm{~min}$ at60 V c 2 layers $\mathrm{A} 12 \mathrm{O} 3 \& \mathrm{HA}$.

The XRD pattern of coated specimens are presented in figure (3.2), (3.3).And the average Hardness Vickers (HV) numbers are listed in Table (1).

b.In invivo test: Clinical observation revealed that all animals moved normally and good health within one week. At sacrifice, no negative clinical observations were found around implant. Also, there were no peri-implant defects at the coronal aspect of implant after 2, 6 and 18 weeks of healing periods. And this was observed through radiographic examination. In which, there were no radiolucency between the implant and adjacent cortical bone.as shown in figure(4)

\section{Mechanical testing:-}

In Table (2) the highest torque mean value was observed after 18 weeks of implantation .And the results of ANOVA test revealed a highly significance difference among all groups of modified implant surfaces at each time interval. In LSD test results, Table (3) revealed a highly significance difference between uncoated implant and coated implant with two layer and mixture of $\mathrm{Al} 2 \mathrm{O} 3$ \&HA and this was for all time interval.

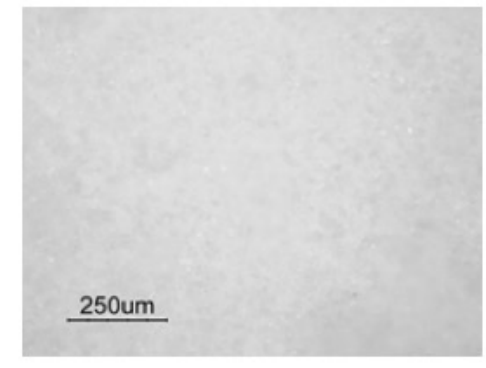

a.5 min $60 \mathrm{~V}$ of $\mathrm{Al}_{2} \mathrm{O}_{3}$

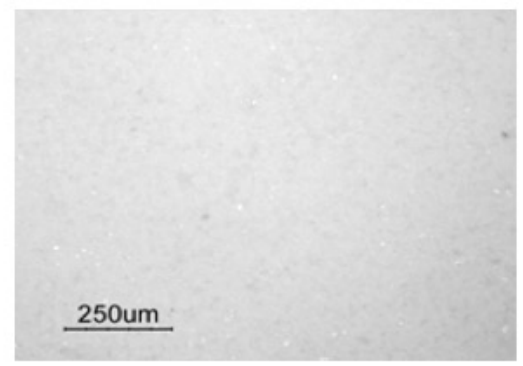

b. $2 \mathrm{~min} 60 \mathrm{~V}$ of mixture $\mathrm{Al}_{2} \mathrm{O}_{3}$ \& $\mathrm{HA}$

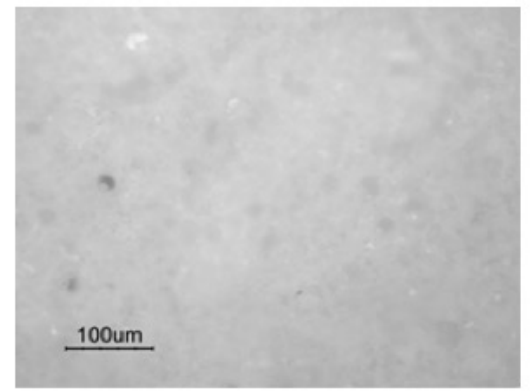

c .2 layers $\mathrm{Al} 2 \mathrm{O} 3 \& \mathrm{HA}$

Fig (1) Optical micrograph views of different coating surface 


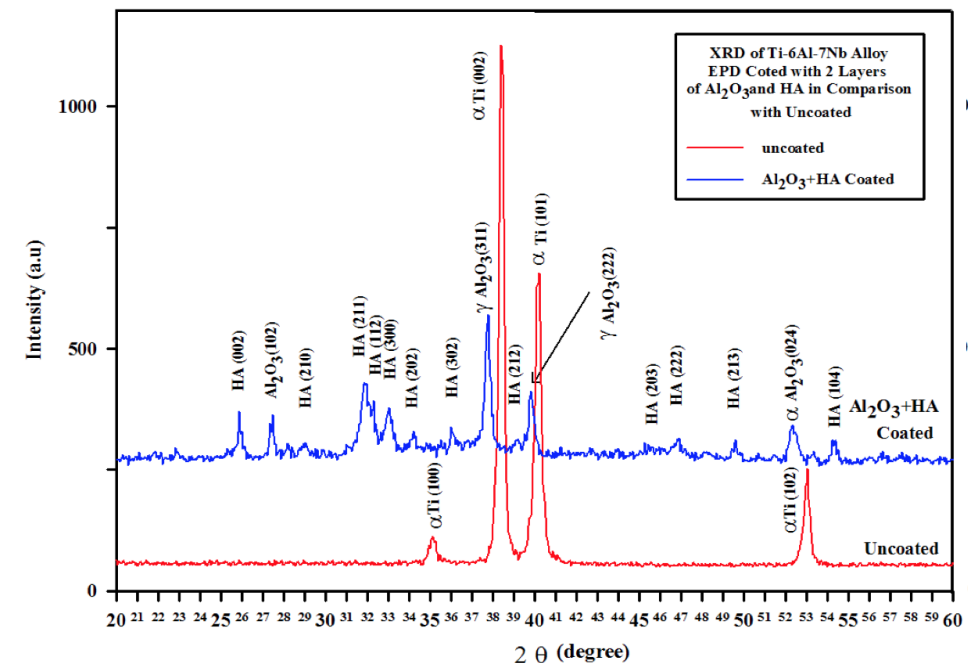

Figure (3)XRD patterns of specimen coated with two layers (A12O3 and HA)

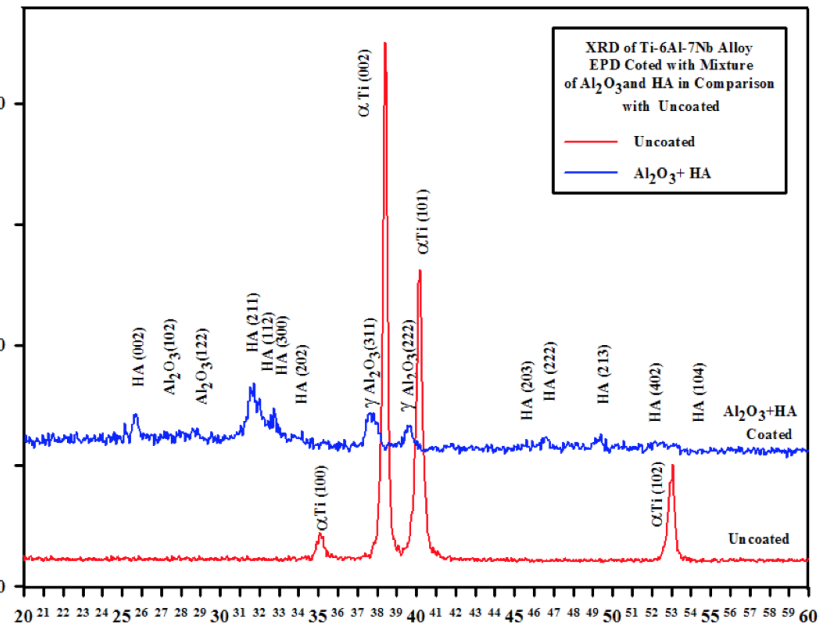

Figure (2): XRD pattern of specimen coated with mixture of $50 \% \mathrm{HA}$ and $50 \% \mathrm{Al} 2 \mathrm{O} 3$
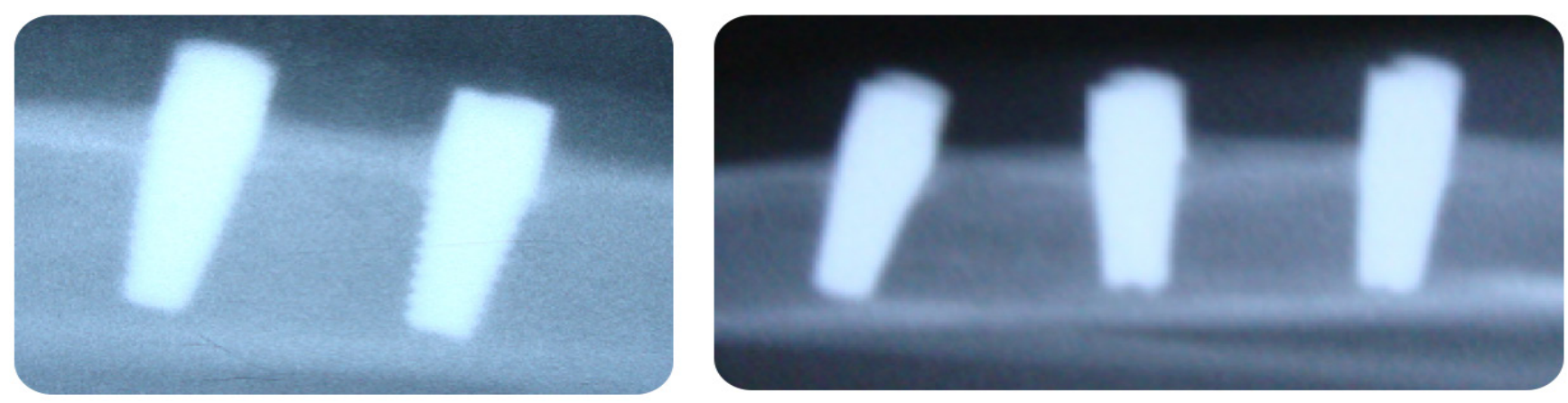

Fig(4) radiographic examination after 18 weeks

Table (1): Average microhardness of the three tested groups of Ti-6Al-7Nb.

\begin{tabular}{|c|c|c|c|}
\hline groups & $\begin{array}{c}\text { Uncoated } \\
\text { Bulk Mat. }\end{array}$ & $\begin{array}{c}\left(\mathrm{Al}_{2} \mathrm{O}_{3} \& H A\right) \\
\text { coated layer }\end{array}$ & Two layer $\left(\mathrm{Al}_{2} \mathrm{O}_{3} \& H A\right)$ \\
\hline Average & 404.5 & 283.3 & 126.5 \\
\hline
\end{tabular}

Table(2) The removal torque mean value of different groups after 2, 6 \& 18 weeks interval s of implantation and ANOVA test

\begin{tabular}{|c|c|c|c|c|c|c|c|}
\hline \multirow[b]{2}{*}{ Groups } & \multirow[b]{2}{*}{$N$} & \multicolumn{2}{|c|}{2 weeks } & \multicolumn{2}{|c|}{6 weeks } & \multicolumn{2}{|c|}{18 weeks } \\
\hline & & $\begin{array}{l}\text { Mean } \\
\mathrm{N} / \mathrm{cm}\end{array}$ & St. d & $\begin{array}{l}\text { Mean } \\
\text { N/cm }\end{array}$ & St.D & $\begin{array}{l}\text { Mean } \\
N / c m\end{array}$ & St.D \\
\hline uncoated implant & 10 & 8.63 & 0.70 & 14.51 & 0.80 & 29.61 & 1.81 \\
\hline $\begin{array}{l}\text { coated implant } \\
\left(\mathrm{Al}_{2} \mathrm{O}_{3} \& \mathrm{~A}\right)\end{array}$ & 10 & 12.42 & 1.34 & 24.25 & 2.48 & 48.11 & 1.59 \\
\hline $\begin{array}{c}\text { Two layer } \\
\left(\mathrm{Al}_{2} \mathrm{O}_{3} \& \mathrm{HA}\right)\end{array}$ & 10 & 12.10 & 1.02 & 23.54 & 2.39 & 46.33 & 1.88 \\
\hline \multirow{2}{*}{ ANOVA test } & F-test & \multicolumn{2}{|c|}{22.262} & 47.714 & & \multicolumn{2}{|l|}{155.705} \\
\hline & $P$ value & \multicolumn{2}{|c|}{0.000 (HS) } & 0.000 & HS) & 0.000 & (HS) \\
\hline
\end{tabular}

Table (3) Multiple Comparison (LSD) among all pairs of implant groups along each period of time independently

\begin{tabular}{|c|c|c|c|c|c|c|c|}
\hline \multirow{2}{*}{ Groups } & \multirow{2}{*}{ Groups } & \multicolumn{6}{|c|}{ Healing periods } \\
\hline & & $2 W$. & Sig. & $6 W$. & Sig. & $18 W$. & Sig \\
\hline \multirow{2}{*}{ uncoated screw } & Coated implant $\left(\mathrm{Al}_{2} \mathrm{O}_{3} \& \mathrm{HA}\right)$ & 0.000 & HS & 0.000 & HS & 0.000 & HS \\
\hline & Two layer $\left(\mathrm{Al}_{2} \mathrm{O}_{3} \& \mathrm{HA}\right)$ & 0.000 & HS & 0.000 & HS & 0.000 & HS \\
\hline Coated implant ( $\mathrm{HA} \& \mathrm{Al}_{2} \mathrm{O}_{3}$ & two layer $\left(\mathrm{HA} \& \mathrm{Al}_{2} \mathrm{O}_{3}\right)$ & 0.512 & NS & 0.409 & NS & 0.042 & $\mathrm{~S}$ \\
\hline
\end{tabular}




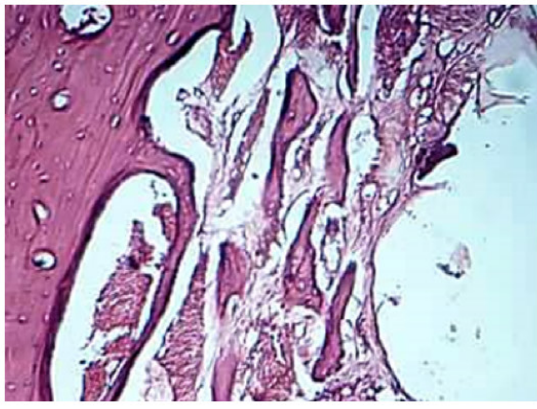

Fig (5)Microphotograph of coated implant with mixture $\mathrm{Al}_{2} \mathrm{O}_{3}$ after 2 weeks H\&E X100

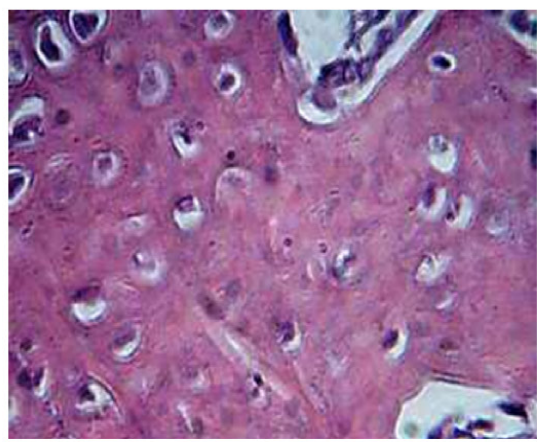

Fig(3)Micrographic view for implant coated with a mixture of (A12O3) after 6 weeks of implantation H\&E X200

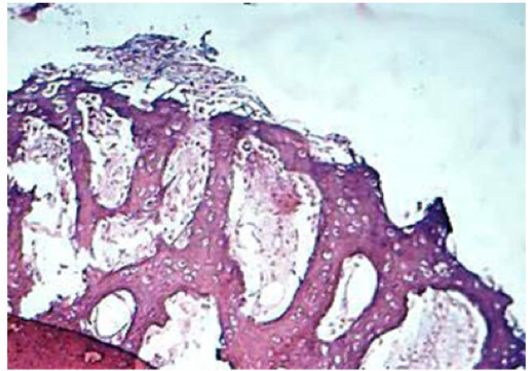

Fig (6)Microphotograph Of coated implant with two layers (A12O3) after 2week

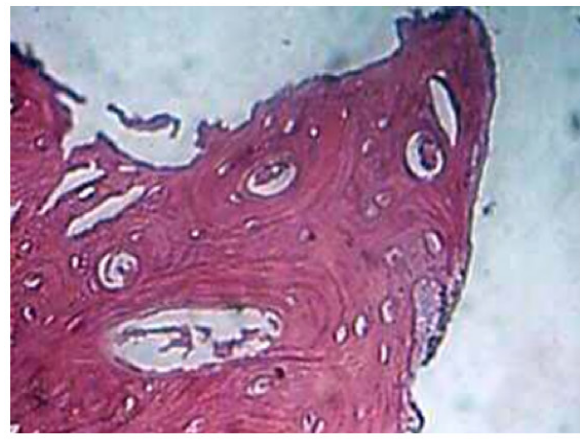

Fig (9)Microphotograph view implant coated with mixture of alumina and hydroxyapatite after 18 weeks of implantation

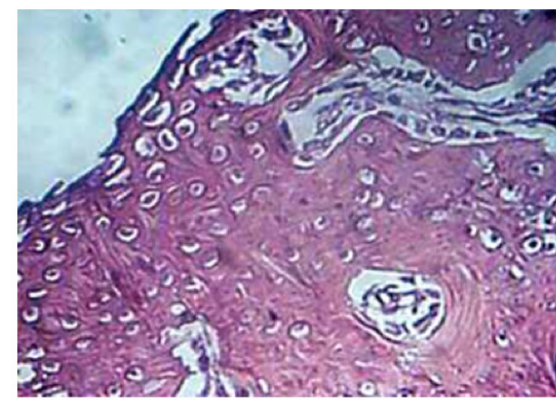

Fig(7)Micrographic view for implant coated with two layers $\left(\mathrm{Al}_{2} \mathrm{O}_{3} \& \mathrm{HA}\right)$ after 6 weeks duration H\&E X200

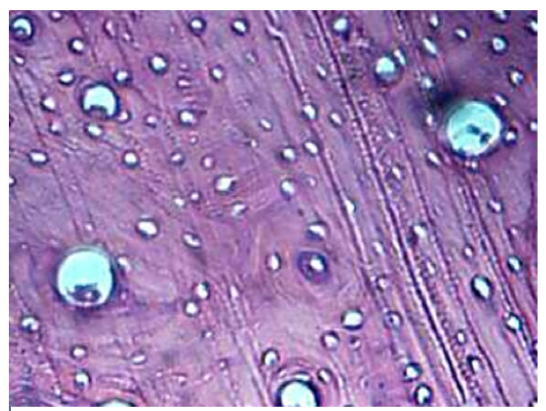

Fig(10)Microphotograph view implant coated with 2 layer of(Al2O3\&HA) after 18 weeks of implantation H\&E X200

\section{Histological test}

Figure (5) illustrates the histological feature of implant coated with mixture of alumina and HA at two weeks. This figure Shows the formation of new bone trabeculae (arrow).while infig(6) view there is a bone trabeculae formed with an implant coated with two layers (alumina and HA) for two week duration . Also huge number of osteocyte cell (OCC). In( fig7) Micrographic view shows a new bone formation with huge number of osteocyte cell (OCC), osteon canal (OC) in implant coated with two layers (alumina and hydroxyapatite) after 6 weeks. Micrographic view in fig (8) shows a new bone formation in rabbit tibia for implant coated with a mixture of alumina and hydroxyapatite after 6 weeks of implantation, with a higher number of osteocyte (OCC).

Microphotograph view for thread Ti-6Al-7Nb alloy implant coated with a mixture of alumina and hydroxyapatite after 18 weeks of implantation shows well developed mature osteon (arrows). H\&E X200as in fig(9)..In higher magnification view, fig(10) shows lamellated and haversian type osteon (arrow), lamella bone (arrow head). H\&E X400.2layers 18 weeks.

\section{DISCUSSIONS}

In microscopic examination, Cracks were not observed across the $1^{\text {st }}$ layer of $\mathrm{Al}_{2} \mathrm{O}$ coating ${ }_{3}$ and mixture of $\mathrm{Al}_{2} \mathrm{O}_{3}$ and $\mathrm{HA}$ which is probably due to the relatively lower thermal expansion coefficient of alumina $\left(\mathrm{Al}_{2} \mathrm{O}_{3}=8.3 \times 10^{-6} / \mathrm{K}\right)$ and when alumina mixed with the HA it will decreases the differences in thermal expansion coefficient of titanium alloy substrate and overcome problems caused by firing shrinkage during sintering that's may leads to the formation of cracks and improve the bond with the substrate ${ }^{(15,9)}$. In the surface morphology of the coated samples weather in the mixture of $\mathrm{Al}_{2} \mathrm{O} 3$ and $\mathrm{HA}$ coating or two layers coating (alumina and HA), there was a fairly uniform distribution of particles and microporous coating layer. In the coating, No cracks was observed suggesting that there was no shrinkage in the coated surface. These findings agreed with Ghiban et al in $2006^{,(15)}$ who found different appearances, from very smooth and small pored aspects to rough and islandlike one. These differences are mainly due to the different deposition conditions of the samples. Also it might be due to differences in particle size of the powder used, HA powder have a very small particle size $(8 \mu \mathrm{m})$ with a narrow size range. $(0.5-35 \mu \mathrm{m}$, $75 \% \mathrm{D}=7.11 \mu \mathrm{m})$ while alumina had about $(8.7 \mu \mathrm{m})$ with very wide size range $(0.3-153 \mu \mathrm{m}, 75 \% \mathrm{D}=42.17$ $\mu \mathrm{m})$.

The result of the study shows that the Vickers 
microhardness value of two layer coating $\mathrm{Al}_{2} \mathrm{O}_{3} \& \mathrm{HA}$ (126.5 HV) while the Vickers microhardness number of the composite of HA and alumina (283.3 HV) was higher than two layers coating. Both studied groups gain less hardness values than control, this may be due to differences in the surface topography of them. The increase in porosity was related to decrease in hardness as found by Gurusamy and Akira, $(2005)^{(\mathbf{1 6})}$

\section{Structural and elemental analysis (XRD)}

The high incidence of HA revealed from the XRD of Ti-6Al-7Nb specimen coated with $50 \%$ HA powder and $50 \%$ alumina may be due to the particle size difference between the two powders (HA and alumina), The HA particle size $(3.8 \mu \mathrm{m})$ was smaller than that for the alumina powder $(8.7 \mu \mathrm{m})$ and this may give more opportunity to the HA particles for charging during the electrophoretic deposition, so that the alumina contribution in the coated layer is much lesser than HA.

The XRD patterns of Ti-6Al-7Nb alloy specimen coated with two layers of alumina and HA shows a crystalline structure of coating layer with domination of the alumina which represent the thick inner layer directly coated the Ti-6Al-7Nb alloy specimen, while the HA represent the outer thin layer of the coating.

\section{In vivo experiments}

In this study, rabbit was selected as an animal model. This is due to the rapid healing of bone as compared with other model ${ }^{(17)}$

Passivation of uncoated implants was performed in this study using HNO3. This was according to the ASTM-F86 .Nitric acid protocol was used with the intention of reducing their surface reactivity, and consequently the corrosion potential, in the highly corrosive biologic milieu ${ }^{(18)}$

\section{Clinical tests}

The radiographic examination in this study, demonstrated a seemingly direct contact between bone and implant, there was no radiolucent zones adjacent to the implanted screw. However, the lack of such zones is not evidence for osseointegration. (19),

\section{Mechanical test}

The removal torque was used for mechanical property of bone implant interface, This technique was present in several experimental and clinical

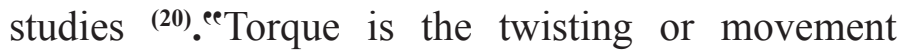
exerted by a force acting at a distance on a body equal to the force multiplied by the perpendicular distance between the line of action of the force and the center of rotation at which it is exerted" (21)

In this study it has been shown that a significant difference in the removal torque mean values between different time periods was present. This agreed with the study Hammad, 2007. (11) "et this increase depends on an increasing bone-metal contact with time as a result of a progressive bone formation and remodeling around the implant during healing, which substantially improved the mechanical capacity."

In the results of the present study, all groups shows a minimum torque mean value after 2 weeks of implantation. And maximum torque mean value after 18 weeks of implantation. Also the maximum increase in torque mean value was observed between 6 and 18 weeks. This increase in torque mean values between $6 \& 18$ weeks may be due to the maturation of woven bone to lamellar bone. And in rabbit, it takes 6 weeks as Sennerby et al in $1992^{(22)}$.

The highest mean torque value was recorded for the Ti-6Al-7Nb screws coated with a mixture of alumina \& HA which was 48.11 N.cm after 18 weeks of implantation, this value indicated that composite formed by mixing of bioinert (alumina) and bioactive (HA) ceramic materials increased the activity of EPD coated layer which improved the bone maturation in bone-implant interface. This result was in agreement with finding of Juna et al, 2003.(23)

In the present study, two layer coated implants (inner $\mathrm{Al}_{2} \mathrm{O}_{3}$ and outer $\mathrm{HA}$ ) result in a highly significant increase in the removal torque mean values as compared with the uncoated specimens within different time periods. This may explain the bioactivity of HA shell and porous bioinert alumina that allow the growth of bone, advance bony integration, and enhance mechanical interlocking with bone.

From the mechanical testing data obtained there was a non-significant difference among two layers(alumina and HA) and mixture of alumina and HA at two and six weeks of healing periods while a significant results appear at 18 weeks this might be due to the continuous maturation and remodeling of the bone around implants so there is no difference in the bioactivity, biomechanical effect of HA, two layers (alumina and HA) and mixture of alumina and HA during maturation of bone, while after 18 weeks the "maturated bone appear to be affected by the type of material on its surface and so that the screw coated with the mixture of alumina and HA required greater removal torque value and a significant difference was revealed between these groups, and this agreed with Clokie and Bell , 2003.(24)

\section{Histological test}

From histological results of this study, the evidence of bone formation on uncoated Ti-6Al-7Nb alloy implant suggests that the woven bone formation 
began in the second weeks after placement. The bone marrow showed active blood vessels, which indicate the beginning of new bone formation. These findings are supported by the work of Shukur in $2015^{(25)}$

The histological features of coated Ti- 6Al$7 \mathrm{Nb}$ implants after 2 weeks of implantation revealed numerous bone spicules, active bone trabeculae formation when compared to the uncoated implant. Osteoblast cell surround trabeculae like beads and osteocyte cell embedded in trabeculae, numerous new blood vessels and bone trabeculae with a huge number of osteocyte cells particularly for that coated with a mixture of alumina and HA and that coated with two layers(alumina and HA) this indicate osteoinductivity of these coatings. And this result was in agreement with the study Habibovic et al in 2005.

After six weeks of implantation, the microscopical observation of uncoated Ti-6Al-7Nb implants showed more bone trabeculae formation, osteocyte cell irregular arranged with osteon canal. While that coated with alumina shows a new bone formation with primitive osteons, and that coated with HA shows an active bone trabeculae and osteon with osteocyte cell irregularly surround it. The mixture of alumina and HA and two layers coated implants shows active process of bone development, indicated by the very active and huge numbers of osteocyte cells, preosteocyte and osteoblast which arranged like a beads. These results were in agreement with Suh et al, 2007(27), which reported that six weeks after implantation, all implants were histologically in direct contact with the surrounding bone with no sign of inflammation with either newly formed bone or marrow tissue.

The Microscopical observation of uncoated Ti$6 \mathrm{Al}-7 \mathrm{Nb}$ implants after 18 weeks of implantation showed a late stage in the development of a future compact bone, osteon. While the coated implants shows a well-developed mature bone following the shape of the screw characterized by a mature osteons and active periosteium with an obvious reversal lines between old and new bone. These results agreed with the findings of Veis et al, $2007^{(28)}$ who confirmed a new cortical layer was formed and a dense connective tissue similar to periosteum was present at bone implant interface after five months

According to the results of this study, one might suggest that the rapid bone formation response to the electrophoretically coated implants with two layers and the mixture of bioinnert gamma Alumina and bioactive Hydroxyapatite are dependent on surface topography and better biocompatibility of the materialwhich greatly effects the biomechanical andhistological properties of the interface.

\section{REFERANCES}

1. Henry PI. Tooth loss and implant replacement. Aust Dent J. 2000; 45:150-72.

2. Saiz E, Goldman M, Gomez-Vega JM, Tomsia AP, Marshall GW, Marshall SJ. In vitro behavior of silicate glass coatings on Ti6Al4V. Biomaterials. 2002; 23:3749-56.

3. Morra M, Cassinelli C, Cascardo G, Cahalan P, Cahalan L, Fini M, Giardino R. Surface engineering of titanium by collagen immobilization. Surface characterization and in vitro and in vivo studies. Biomaterials. 2003; 24:4639-54.

4. Textor M, Sitting C, Frauchiger V, Tosatti S, Brunnett DM. Properties and Significance of Natural Oxide Film on Titanium and Its Alloys. In: Titanium in Medicine. Brunette DM, Tengvall P, Textor M, Thomsen P, editors. Berlin \& Heidlborg : Springer-Verlag. 2001; 172-230.

5. Puleo DA, Kissling RA, Sheu MS. A technique to immobilize bioactive proteins, including bone morphogenetic protein-4 (BMP-4), on titanium alloy. Biomaterials. 2002; 23: 20792087.

6. Yamaguchi S \& Yao T. Development of Bioactive Alumina-Wollastonite Composite by Electrophoretic Deposition. Key Engineering Materials. 2005; 284 - 286. Bioceramics. 17:863-868.

7. Kehoe S. Optimisation of Hydroxyapatite (HAp) for Orthopaedic Application via the Chemical Precipitation Technique. A PhD thesis, School of Mechanical and Manufacturing Engineering, Dublin City University, 2008.

8. Meng X, Kwon T, Kim K. Hydroxyapatite coating by electrophoretic deposition at dynamic voltage. Dent Mater. 2008; 27(5): 666-671

9. Wang Z, Ni Y, Huang J. Fabrication and characterization of HAp /A12O3 composite cating on titanium substrate. J Biomed Sci and Eng. 2008; 1:190-194.

10. Zhitomirsky I. Ceramic Films Using Cathodic Electrodeposition. J Minerals Metals \& Materials Society. 2000; 52 (1):1-11

11. Hammad TI. Histological and Mechanical Evaluation of Electrophoretic Bioceramic Deposition on Ti- 6Al- $7 \mathrm{Nb}$ Dental Implants, A PhD thesis, College of Dentistry, University of Baghdad, 2007.

12. Salman YS A study of Electrophoretic Deposition of Alumina and Hydroxyapatite on Tapered Ti-6Al-7Nb Dental Implants: Mechanical and Histological Evaluation A PhD thesis, College of Dentistry, University of Baghdad, 2011

13. Baker MA, Assis SL, Higa OZ, Costa I. Nanocomposite hydroxyapatite formation on a Ti-13Nb-13Zralloy exposed in a MEM cell culture medium and the effect of $\mathrm{H} 2 \mathrm{O} 2$ addition, Acta Biomaterialia. 2009; 5:63-75.

14. Sarkar P, De D, Rho H. Synthesis and microstructural manipulation of ceramics by electrophoretic deposition. J Mater Sci. 2004; 39: 819-823.

15. Ghiban B, Jicmon G, Cosmeleata G. Structural Investigation of Electrodeposited Hydroxyapatite on titanium supports. Romanion J Physics. 2006; 51:173-180.

16. Gurusamy S \& Akira k. Effect of processing parameters on microstructure and mechanical properties of zirconia/ alumina composite coatings by gas tunnel type plasma spraying .Trans JWRI. 2005; 34(1): 43-47 
17. Kim E.S., Park E.J., Choung P.H. Platelet concentration and its effect on bone formation in calvarial defects: An experimental study in rabbits: J Prosth Dent 2001; 86: 428-33.

18. Callen BW, Sodhi RN, Griffiths K. Examination of clinical surface preparation on titanium and Ti.6Al.4V by $\mathrm{x}$-ray photoelectron spectroscopy and nuclear reaction analysis. Progr Surf Sci. 1995; 50:269-79.

19. Huang HM, Pan LC, Lee SY, Chiu CL, Fan KH, Ho KN. Assessing the implant/bone interface by using natural frequency analysis. Oral surg Oral Med Oral Patho Oral Radiol Endod. 2000; 90:285-91.

20. Karacsa A, Joob Fancsalyb A, Divinyib T, Peto"a G, Kova'cha G. Morphological and animal study of titanium dental implant surface induced by blasting and high intensity pulsed Nd-glass laser. Mater Sci and Eng. 2003, C (23): 431-435.

21. Hoda Y, Allyn L, Jack R, Saul W. Analysis of changes in Implant screws subject to occlusal loading: A Preliminary Analysis. Implant Dent. 2005; 14:378-385.

22. Sennerby L, Thomsen P, Ericson EL. A Morphometric and Biomechanic Comparison of Titanium Implants Inserted in Rabbit Cortical and Cancellous Bone. Int J Oral Maxillofac Impl. 1992; 7(1):62-70.

23. Juna YK, Kimb WH, Kweonb OK, Hong SH. The fabrication and biochemical evaluation of alumina reinforced calcium phosphate porous implants. Biomaterials. 2003; 24, 21:3731-3739.

24. Juna YK, Kimb WH, Kweonb OK, Hong SH. The fabrication and biochemical evaluation of alumina reinforced calcium phosphate porous implants. Biomaterials. 2003; 24, 21:3731-3739.

25. Shukur BN and Jassim RK.Evaluation of nano surface modification on CPTi dental implant using chemical method: mechanical and histological evaluation J Bagh College Dent 2015 Vol. 27(3),8-14

26. Habibovic P, Li J, van der Valk CM, Meijer G, Layrolle P, van Blitterswijk CA, Groota K. Biological performance of uncoated and octacalcium phosphate-coated Ti6Al4V. Biomaterials. 2005; 26:23-36.

27. Suh JY, Jeung OY, Choi BJ, Park JW. Effects of a novel calcium titanate coating on the osseointegration of blasted endosseous implants in rabbit tibiae. Clin Oral Impl Res. 2007; 18:362-369

28. Veis AA, Papadimitriou S, Trisi P, Tsirlis A, Parissis NA, Kenealy JN. Osseointegration of Osseotite and machinedsurface titanium implants in membrane-covered criticalsized defects: a histologic and histometric study in dogs. Clin Oral Impl Res. 2007; 18:153- 160. 